\title{
Research on the Ageing Detection and Assessment Method of Silicone Rubber Materials Based on the Multi-Technology Fusion
}

\author{
Liangyuan Chen*, Dajian Li and Jian Zhao \\ Guangxi Power Grid Company Limited Electric Power Research Institute, nanning, 530023, China \\ ${ }^{*}$ Corresponding author
}

\begin{abstract}
The ageing properties, detection technology and assessment method were researched in the paper. First, the influence on the silicone rubber materials of transmission and distribution equipment was analyzed. Second, based on the mutitechnology fusion of macroscopic and microscopic detection method, the mechanical performance, electrical performance, hydrophobicity and microscopic structure of $110 \mathrm{kV}$ and above silicone rubber materials was tested. Then, the strong characteristics reflecting the ageing properties were extracted and graded. Finally, the linear weighting method was used for the assessment of ageing state, and the maintenance strategy was mapped out. The assessment results can well reflect the ageing state of the silicone rubber materials, and also are available and helpful for the equipment management departments.
\end{abstract}

Keywords-silicone rubber materials; ageing; muti-technology fusion; weighting; assessment

\section{INTRODUCTION}

The silicone rubber materials are usually used in composite insulators and bushings of power transformers, arresters, voltage or current transformers, and so on. The composite insulators, which are mainly made of the fiber reinforced plastic rods and silicone rubber materials, have the performance of light, high strength and strong pollution resistance. They overcome the problems of easy ageing of conventional polymer materials such as epoxy resin, and are widely used in the power system. However, due to the reasons of material, formulation, process, manufacturing level, and adverse environmental impact of perennial running outdoors, high temperature, high humidity, acid rain, dust, and so on, silicone rubber insulation appears hard, brittle, surface cracking, hydrophobic, local heating, mechanical strength decreasing and other phenomena ${ }^{[1]}$. The silicone rubber with the decreasing insulation performance causes multiple flashover and damage accidents, which affect the safe and stable operation of the power grid ${ }^{[2-3]}$. At present, there is no uniform standard for evaluating the ageing status of silicone rubber materials at home and abroad. Many ways have been presented to evaluate ageing condition, however, it is still difficult to effectively judge the ageing status of materials and to formulate operational maintenance strategies.

In the paper, based on the analysis of the influence factors on the performance and the muti-technology fusion of macroscopic and microscopic detection method, the strong characteristics of the ageing characteristics of the silicone rubber insulation materials were extracted and classified, and the linear weighting method was used to evaluate the ageing status.

\section{INFLUENCE FACTORS ANALYSIS}

\section{A. Characteristics of the Silicone Rubber Materials}

The silicone rubber is an elastomer made by ring-opening polymerization of cyclic polysiloxanes, of which molecular backbone consists of a silicon-oxygen bond ( $\mathrm{Si}-\mathrm{O})$ with higher bond energy $(459.8 \mathrm{~kJ} / \mathrm{mol})$. The commonly used silicone rubber is room temperature vulcanized (RTV) silicone rubber, liquid vulcanized silicone rubber (LSR) and high temperature vulcanized silicone rubber (HTV). Considering the influence of material, formulation, process, manufacturing level, the performance between RTV, LSR and HTV is shown in Table I. It is shown that HTV has the highest molecular weight, the most stable bond energy, and the best curing conditions of high temperature glue ${ }^{[4]}$. That means the heat resistance, oxygen ageing, weather resistance, UV resistance, electrical leakage resistance and corrosion resistance are the most excellent in silicone rubber insulation.

TABLE I. THE PERFORMANCE BETWEEN RTV, LSR AND HTV

\begin{tabular}{|c|c|c|c|c|}
\hline \multirow{2}{*}{\multicolumn{2}{|c|}{ Parameter }} & \multicolumn{3}{|c|}{ The Silicone Rubber Type } \\
\hline & & $R T V$ & $L S R$ & $H T V$ \\
\hline \multicolumn{2}{|c|}{ Raw rubber state } & liquid & liquid & semisolid \\
\hline \multicolumn{2}{|c|}{ Viscosity(mPa.s) } & $\begin{array}{l}5 \times 10^{3} \sim \\
1 \times 10^{5}\end{array}$ & $\begin{array}{c}2 \times 10^{2} \sim \\
1 \times 10^{4}\end{array}$ & $2 \times 10^{7}$ \\
\hline \multirow{3}{*}{$\begin{array}{l}\text { Curing } \\
\text { condition }\end{array}$} & Temperature $\left({ }^{\circ} \mathrm{C}\right)$ & $80 \sim 100$ & 25 & $150 \sim 170$ \\
\hline & Pressure(MPa) & $5 \sim 10$ & 0.1 & $10 \sim 15$ \\
\hline & Time(min) & $30 \sim 60$ & $1440 \sim 2160$ & $30 \sim 60$ \\
\hline \multicolumn{2}{|c|}{ Molar mass $\left(\times 10^{5} \mathrm{~g} / \mathrm{mol}\right)$} & $1 \sim 10$ & $1 \sim 10$ & $30 \sim 80$ \\
\hline \multicolumn{2}{|c|}{ Polymerization degree $\left(\times 10^{3}\right)$} & $0.1 \sim 1$ & $0.1 \sim 1$ & $5.0 \sim 10$ \\
\hline \multicolumn{2}{|c|}{ Volume resistivity $(\Omega \cdot \mathrm{cm})$} & $10^{13} \sim 10^{15}$ & $10^{13} \sim 10^{15}$ & $10^{13} \sim 10^{15}$ \\
\hline \multicolumn{2}{|c|}{ Dielectric strength $(\mathrm{kV} / \mathrm{mm})$} & $20.0 \sim 26.0$ & $20.0 \sim 22.0$ & $\begin{array}{c}20.0 \sim 24 . \\
0\end{array}$ \\
\hline \multicolumn{2}{|c|}{ Dielectric constant } & $2.0 \sim 5.0$ & $2.0 \sim 5.0$ & $2.0 \sim 5.0$ \\
\hline
\end{tabular}

B. Influence Factors

The factors that affect the performance of the silicone rubber materials are not only related to the quality problems of 
material structure, formulation, process and manufacturing level, but also are related to the harsh environment outdoors, such as compounding agent, high temperature, high humidity, acid rain, dust, ozone, UV and so on. The ageing phenomenon of the silicon rubber insulation materials such as Hard brittle powder, cracking, loss of hydrophobicity, local heating and mechanical strength decreased will appear under the factors mentioned before.

The silicone rubber ageing is mainly manifested in the following aspects: 1) the surface hydrophobicity decreases, hydrophobicity migration time gets longer, and recovery ability weakens; 2) powder phenomenon appears on the surface; 3) tracking and erosion or other serious phenomenon appears in the heavy pollution area; 4) hardness and tear resistance weakens; 5) the surface of the umbrella skirt and other impurities of chemical elements increases, and the chemical structure of silicone rubber has been severely destructed; 6) surface roughness appears, or number of pores increases, and the material loses.

\section{The Multi-Technology Fusion Detection Method}

\section{A. The Detection Method and the Strong Characteristics}

At present, the macroscopic detection method such as the hydrophobicity class (HC) detection ${ }^{[5]}$, leakage current detection, hardness detection, tensile strength detection are used to research the characteristics of the silicon rubber materials. For example, the higher the grade of hydrophobicity measurement, the worse the ageing degree of insulators. The macroscopic detection method focus on the mechanical, electrical and hydrophobic properties. Besides, the microscopic detection method is also used such as the scanning electron microscope (SEM) detection, the fourier transform infrared spectroscopy (FTIR) detection ${ }^{[6]}$, thermally stimulated current (TSC) detection, and so on.

Compared with the advantages and disadvantages between the macroscopic and microscopic detection method, detection was performed on the samples related to the arresters, voltage or current transformers and composite insulators. The detection consists of the visual inspection, tracking and erosion detection, hydrophobicity detection, tearing strength detection, tensile strength detection, tensile elongation detection, hardness detection, Flame retardancy detection, fourier transform infrared spectroscopy detection, X-ray diffraction, X-ray photoelectron spectroscopy and scanning electron microscopy. The detection results of seven samples are shown in Table II. As is shown, the samples, of which appearance is normal, have the lower hardness, higher tensile strength, tensile elongation and hydrophobicity, and less variation than the other same type ones. The appearance of obvious cracks and powder, high hardness and low mechanical properties, is indicating that the brittleness of materials increases. The results of fourier transform infrared spectroscopy of \#5 sample are shown in the figure. The content of Si-O bond increases, while the content of $\mathrm{Si}-\mathrm{C}$ bond decreases. It shows that the $\mathrm{Si}-\mathrm{O}$ bond is bonded by the free silicon and oxygen when the $\mathrm{Si}-\mathrm{C}$ bond breaks. Comparing the absorbance between the surface and the inside of the sample, the ageing state can be derived. Synthesized the detection results, $\# 2, \# 4$ and $\# 6$ sample has the severe ageing status.
TABLE II. THE DETECTION RESULTS

\begin{tabular}{|c|c|c|c|c|c|c|}
\hline \multirow{2}{*}{ Detection Items } & \multicolumn{6}{|c|}{ Number of the Samples } \\
\hline & $\# 1$ & $\# 2$ & $\# \mathbf{3}$ & $\# 4$ & $\# 5$ & \#6 \\
\hline Visual inspection & normal & $\begin{array}{l}\text { crazing, } \\
\text { powderi } \\
\text { ng }\end{array}$ & normal & $\begin{array}{l}\text { crazing, } \\
\text { powderi } \\
\text { ng }\end{array}$ & normal & $\begin{array}{l}\text { crazing, } \\
\text { powderi } \\
\text { ng }\end{array}$ \\
\hline Hardness & 70.5 & 39.5 & 34.5 & 76.0 & 65.0 & 83.0 \\
\hline Flame retardancy & Failed & FV-0 & FV-0 & FV-0 & FV-0 & FV-0 \\
\hline Tensile strength & 5.17 & 2.33 & 3.85 & 1.99 & 3.57 & 1.78 \\
\hline $\begin{array}{l}\text { Tensile } \\
\text { elongation }\end{array}$ & 186.50 & 244.65 & 285.75 & 72.2 & 227.6 & 43.1 \\
\hline Tearing strength & 9.71 & 15.08 & / & 10.63 & 14.07 & 13.75 \\
\hline $\begin{array}{l}\text { Tracking and } \\
\text { erosion }\end{array}$ & $\begin{array}{l}\text { burn } \\
\text { through( } \\
17 \mathrm{~min}) \\
\end{array}$ & pass & $\begin{array}{l}\text { burn } \\
\text { through( } \\
12 \mathrm{~min}) \\
\end{array}$ & $\begin{array}{l}\text { burn } \\
\text { through( } \\
75 \mathrm{~min})\end{array}$ & $\begin{array}{l}\text { burn } \\
\text { through( } \\
3 \mathrm{~h})\end{array}$ & pass \\
\hline Hydrophobicity & $\mathrm{HC} 2$ & $\mathrm{HC} 7$ & $\mathrm{HC} 1$ & $\mathrm{HC} 3$ & HC5 & $\mathrm{HC} 2$ \\
\hline $\begin{array}{l}\text { Fourier transform } \\
\text { infrared } \\
\text { spectroscopy }\end{array}$ & normal & $\begin{array}{l}\text { More } \\
\text { Si- } \\
\text { O,less } \\
\text { Si-C }\end{array}$ & normal & $\begin{array}{l}\text { More } \\
\text { Si- } \\
\text { O,less } \\
\text { Si-C }\end{array}$ & $\begin{array}{l}\text { More } \\
\text { Si-O }\end{array}$ & $\begin{array}{l}\text { More } \\
\text { Si- } \\
\text { O,less } \\
\text { Si-C }\end{array}$ \\
\hline $\begin{array}{l}\text { Scanning electron } \\
\text { microscopy }\end{array}$ & $\begin{array}{l}\text { Little } \\
\text { Rough } \\
\text { surface }\end{array}$ & $\begin{array}{l}\text { Big } \\
\text { pit,Rou } \\
\text { gh } \\
\text { surfaces } \\
\text {,grain }\end{array}$ & $\begin{array}{l}\text { Little } \\
\text { Rough } \\
\text { surface }\end{array}$ & $\begin{array}{l}\text { Big } \\
\text { pit,Rou } \\
\text { gh } \\
\text { surfaces } \\
\text { grain } \\
\end{array}$ & Big pit & $\begin{array}{l}\text { Big } \\
\text { pit,Rou } \\
\text { gh } \\
\text { surfaces } \\
\text {,crackle }\end{array}$ \\
\hline
\end{tabular}

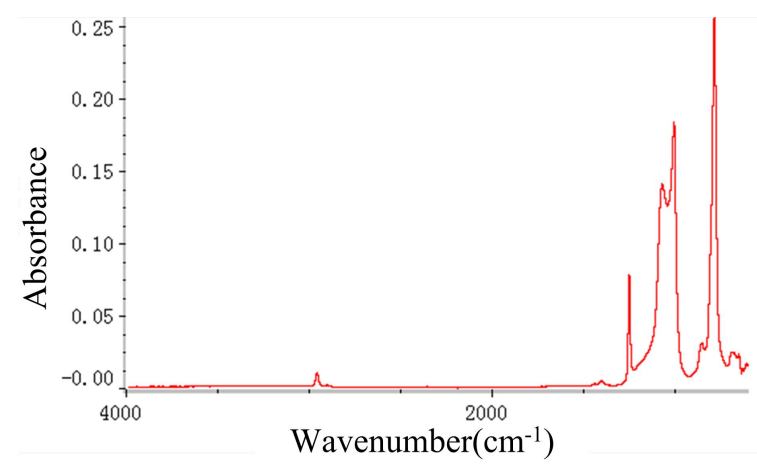

(a)

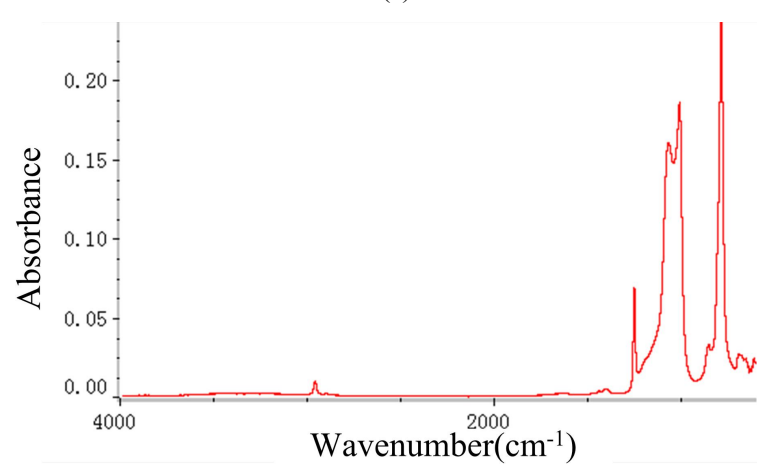

(b)

FIGURE I. FOURIER TRANSFORM INFRARED SPECTROSCOPY OF \#5 SAMPLE:(A) THE SURFACE (B)THE INSIDE

From the results shown above, the appearance, hardness, hydrophobicity, tensile strength and fourier transform infrared spectroscopy detection method extracted can be effectively reflecting the ageing properties. They are the strong 
characteristics for the ageing state measurement and assessment.

\section{B. The ageing Assessment Method}

The ageing assessment method based on the linear weighting method is presented. First, based on the classification of the strong characteristics detection results, the assessment level of the classification detection result is divided into four levels: I, II, III and IV. The weights are assigned against each assessment level. The detection result classification methods are shown in Table III. The ageing result assessment level, which synthesize the detection result, is also divided into four levels: I, II, III and IV, of which Level I is no obvious ageing that means the equipment can continue to run; Level II is the minor ageing that means the equipment can continue to run, but need tracking detection; Level III is the obvious ageing that means the equipment requires maintenance which is taken the spray paint or outsourcing new insulation coat; Level IV is the severe ageing that means the equipment need to withdraw from the operation, in addition, the source and the same batch equipment need to be integrally detected. The result assessment method is shown in Table IV.

TABLE III. THE DETECTION RESULT CLASSIFICATION METHODS

\begin{tabular}{|c|c|c|c|c|c|c|}
\hline & \multirow{2}{*}{ Characteristics } & \multicolumn{4}{|c|}{ The Detection Result Classification Level } & \multirow{2}{*}{$\begin{array}{c}\text { Weight } \\
(\%)\end{array}$} \\
\hline & & Level I & Level II & Level III & Level IV & \\
\hline 1 & appearance & $\begin{array}{l}\text { No cracks } \\
\text { and } \\
\text { powers }\end{array}$ & $\begin{array}{c}\text { several } \\
\text { cracks } \\
\text { and } \\
\text { powers }\end{array}$ & $\begin{array}{l}\text { A few } \\
\text { cracks, } \\
\text { but no } \\
\text { powers }\end{array}$ & $\begin{array}{l}\text { Many } \\
\text { cracks } \\
\text { and } \\
\text { powers }\end{array}$ & 20 \\
\hline 2 & Hardness & $\mathrm{HC} 1-\mathrm{HC} 2$ & $\mathrm{HC} 3-\mathrm{HC} 4$ & HC5 & HC6-HC7 & 20 \\
\hline 3 & Hydrophobicity & $>4.5$ & $4.0 \sim 4.5$ & $2.5 \sim 4.0$ & $<2.5$ & 20 \\
\hline 4 & Tensile strength & $50 \sim 65$ & $65 \sim 70$ & $70 \sim 80$ & $>80$ & 10 \\
\hline 5 & $\begin{array}{l}\text { Fourier transform } \\
\text { infrared } \\
\text { spectroscopy }\end{array}$ & normal & $\begin{array}{c}\text { Small } \\
\text { changes }\end{array}$ & $\begin{array}{l}\text { Medium } \\
\text { changes }\end{array}$ & $\begin{array}{c}\text { Big } \\
\text { changes }\end{array}$ & 30 \\
\hline & Scores & 300 & 200 & 100 & 0 & -- \\
\hline
\end{tabular}

TABLE IV. THE RESULT ASSESSMENT METHODS

\begin{tabular}{|c|l|c|c|c|}
\hline \multicolumn{2}{|c|}{$\begin{array}{c}\text { Ageing } \\
\text { assessment } \\
\text { level }\end{array}$} & Meaning & Scores & $\begin{array}{c}\text { Operation and maintenance } \\
\text { strategy (for the same batch ) }\end{array}$ \\
\hline 1 & Level I & no obvious ageing & $200-300$ & continue to run \\
\hline 2 & Level II & the minor ageing & $140-199$ & $\begin{array}{c}\text { continue to run, but need tracking } \\
\text { detection }\end{array}$ \\
\hline 3 & Level III & $\begin{array}{c}\text { the obvious } \\
\text { ageing }\end{array}$ & $91-139$ & requires maintenance \\
\hline 4 & Level IV & the severe ageing & $0-90$ & need to withdraw \\
\hline
\end{tabular}

While using the ageing assessment method, it can be seen that the ageing assessment level of the sample \#2, \#4 and \#6 are Level IV. And the ageing assessment result is consistent with the detection result shown in Part A, Section III. So the equipment need to withdraw from the operation, in addition, the source and the same batch equipment need to be integrally detected. Again, the ageing assessment level of the sample \#1 and \#3 are Level I, and the ageing assessment level of the sample \#2 is Level II. The operation and maintenance strategy is shown in TABLE IV.

\section{CONCLUSION}

Through the research on the ageing characteristics and factors, detection technology and ageing evaluation methods of silicone rubber materials, the following conclusions are obtained:

1) The insulation performance of silicone rubber materials has inevitably declined in different degrees after a period of operation;

2) By using the multi-technology fusion methods for detection, five strong characteristics such as appearance, hardness, hydrophobicity, tensile strength, and Fourier transform infrared spectroscopy are extracted and can better reflect the performance of materials;

3) The ageing assessment method based on the linear weighting method is established, which help the operators take corresponding maintenance strategy.

4) The ageing assessment result (severe ageing) is consistent with the detection result.

\section{REFERENCES}

[1] K. YUKIHIRO, "Deterioration of silicone rubber for polymer insulators by corona discharge and effect of fillers," Annual Report of Electrical Insulation and Dielectric Phenomena, Atlanta, USA, pp.72-79,1998

[2] Ali, Mansab, and R. Hackam, "Effects of saline water and temperature on surface properties of HTV silicone rubber," IEEE Transactions on Dielectrics \& Electrical Insulation, vol. 15, pp.1368-1378, 2008.

[3] R. S. Gorur, R. S. Gorur, G. G. Karady, et al, "Aging in silicone rubber used for outdoor insulation," IEEE Transactions on Power Delivery, vol.7, pp.525-538, 1992.

[4] W.Song, W. W. Shen, G. J. Zhang, et al, “Aging characterization of high temperature vulcanized silicone rubber housing material used for outdoor insulation," IEEE Transactions on Dielectrics \& Electrical Insulation, vol.22, pp.961-969, 2015.

[5] L.Zhao,W. D. Li, Y. H. Wei, et al, "Study on hydrophobicity recovery and measurement of aged sillicone rubber material," 2015 IEEE 11th International Conference on the Properties and Applications of Dielectric Materials, Sydney, pp.696-699, July 2015.

[6] R Anyszka, D. M. Bieliński,and M. Jędrzejczyk, "Thermal behavior of silicone rubber-based ceramizable composites characterized by Fourier transform infrared (FT-IR) spectroscopy and microcalorimetry," Applied Spectroscopy, vol.67, pp.1437-1440, 2013.1989 